UPPSALA UNIVERSITET

Working Paper 2005:4

Department of Economics

\title{
Antidepressants and the Suicide Rate: Is There Really a Connection?
}

Matz Dahlberg and Douglas Lundin 
Department of Economics Uppsala University

P.O. Box 513

SE-751 20 Uppsala

Sweden

Fax: +46 184711478
Working paper 2005:4

February 2005

ISSN 0284-2904

AntidePREssants AND the SUicide Rate:

Is There ReAlly a ConNection?

Matz Dahlberg And Douglas Lundin

Papers in the Working Paper Series are published on internet in PDF formats.

Download from http://www.nek.uu.se

or from S-WoPEC http://swopec.hhs.se/uunewp / 


\title{
Antidepressants and the Suicide Rate: Is There Really a Connection?*
}

\author{
Matz Dahlberg ${ }^{\perp}$ and Douglas Lundin
}

This version: January 2005

\begin{abstract}
Recent research claims that the major part of the observed reduction in suicide rates during the 1990's can be explained by the increase in the prescription of antidepressants. This conclusion is however based on research that only looks at raw correlations; confounding effects from other variables are not controlled for. Using a rich data set, we reinvestigate the issue. After controlling for other covariates, observed as well as unobserved, that might affect the suicide rate, we find, overall, no statistically significant effects from antidepressants on the suicide rate; when we do get significant effects, they are positive for young persons. Regarding the latter result, more research is needed before any firm policy conclusion can be made.
\end{abstract}

Keywords: Suicide, Antidepressants, Poisson fixed effects

JEL Classification: I12, C23

\footnotetext{
* We are grateful to Agneta Öjehagen, Lars Lindvall and seminar participants at Uppsala University and at the 2004 Arne Ryde Symposium on the "Economics of Substance Use" in Lund for valuable comments and discussions.

${ }^{\perp}$ Department of Economics, Uppsala University, PO Box 513, SE-751 20 Uppsala, Sweden. E-mail: matz.dahlberg@nek.uu.se

Läkemedelsförmånsnämnden, Box 55, 17111 Solna. E-mail: douglas.lundin@lfn.se
} 


\section{Introduction}

The introduction of a new kind of antidepressants, the SSRIs (selective serotonin reuptake inhibitors), in the early 1990s has in many countries led to a very large increase in the prescription rate of antidepressants. Recent research claims that the major part of the observed reduction in suicide rates during the same period can be explained by an increase in the prescription of antidepressants. The reason one might expect there to be a negative relation between the suicide rate and antidepressant prescriptions, is the fact that most individuals who commit suicide are depressed (Cheng, 1995), and that very few of these have received adequate treatment (Isacsson et al., 1992; Isacsson et al., 1994; Isometsä et al., 1994). Isacsson (2000) finds that the suicide rate decreased by $19 \%$ in parallel with the increased use of antidepressants, from 23.3 suicides per 100,000 inhabitants in 1991 to 18.8 in $1996($ rho $=-0.90, \mathrm{P}<0.05)$. The annual difference in suicide rates and in the use of antidepressants did not correlate with each other, but the differences between the consecutive 3-year periods did. He further finds that there were no demographic groups with regard to age, gender or county in which the suicide rate decreased in the absence of an increased usage of antidepressants. However, for women under 30 and over 75 years of age, and in 4 of the 23 counties, suicide rates remained unchanged despite an increased use of antidepressants. Isacsson (2000) finds similar patterns for Denmark, Norway and Finland. The author concludes that his naturalistic study is not conclusive, but that the increased use of antidepressants appears to be one of the contributing factors to the decrease in the suicide rate. In another study for Sweden, Carlsten et al. (2001), examined data for the period 1977-1997 and found that suicide rates declined over the whole study period, but the rate of decline accelerated after the SSRIs were introduced in 1990. Rihmer (2001) finds the same to be true in Hungary. Prescriptions of antidepressants rose steeply after the introduction of SSRIs in the 
early 1990s and rates of suicide declined, despite steep increases in unemployment and alcohol consumption.

Unlike the earlier studies, Hall et al. (2003) do not find the increase in the prescription of antidepressants during the 1990 s to be accompanied by a decline in overall suicide rates. There was a marked decrease in suicide rates among older men and women, but this was offset by increases in younger adults. But since the older age groups are the ones having the highest exposure to antidepressants, Hall et al. (2003) also come to the conclusion that there seems to be an association - less suicides if antidepressants are prescribed to more patients.

The only study not coming to this conclusion is Barbui et al. (1999), who find no association between suicide rates and antidepressants use in Italy in the period 1986-96, the period during which the SSRIs were introduced.

All of the above studies base their conclusions on raw correlations between the two variables "suicide rate" and "prescription rate of antidepressants". They do not perform any statistical analysis where they try to control for confounding factors. Ludwig and Marcotte (2004) perform a more careful analysis, using data from 27 different countries collected over nearly 20 years, where they control for covariates. They find that an increased usage of antidepressants translates into less suicide. However, the data they use do not contain information about the prescription rates in different age groups, which does not allow them to investigate whether there are any differences between age groups.

In this paper we reinvestigate whether the increased prescription of antidepressants can explain the simultaneous reduction in suicide rates using more detailed data that allows us to control for other covariates, observed as well as unobserved, that might affect the suicide rate. We have data available on sold quantity of antidepressants and suicide rates disaggregated in the following dimensions: gender, age group, county and year. The data 
provides us with enough variation in the two variables to allow us to run multivariate regression models, where we control for unemployment, alcohol sales, as well as unobserved covariates which are specific to a county, an age group or a certain year.

We find no statistically significant effects from antidepressants on the suicide rate when assuming that the effects are the same for all age groups. However, when allowing for heterogeneous effects on different age groups, we find a positive and statistically significant effect of the sold quantities of antidepressant on the suicide rate of young persons (under the age of 25). The latter result seems to be robust to several alternative model specifications.

\section{Data and descriptive statistics}

\subsection{Data}

The data set used for this study contains information on suicides and sold quantity of antidepressants over the years 1990-2000. The information is available separately for county, gender, and different age groups, i.e. an observation in the data set gives the number of suicides and sold quantity of antidepressants: for a specific year, in a specific county, for a specific age group (5-year intervals), and separately for men and women. ${ }^{1}$ Data on suicides are taken from the National Health Board's mortality register, which registers all deaths by cause. Data on sold quantity of antidepressants are taken from Apoteket AB, the government owned retail monopoly for prescription drugs, which collects comprehensive data on drugs sales.

Table 1 gives some summary statistics. Presumed suicides are classified into one of two categories: certain and uncertain. In this study we will mainly use certain and uncertain suicides added together. According to specialists in the field, approximately $70-80 \%$ of those

\footnotetext{
${ }^{1}$ We do not use the rare cases of suicides for those under the age of 10 . The age group intervals are as follows; $10-14,15-19, \ldots, 75-79$, and 80-99.
} 
suicides that are classified as uncertain are true suicides, so the convention is to perform the analysis on certain and uncertain added together, rather than only using certain suicides in the analysis with the argument that this will minimize bias. ${ }^{2}$ Our measure of sold quantity of antidepressants is DDD, Defined Daily Dose, which is the assumed average daily dose of the drug when it is used by adults in its main indication. The DDD is set by the World Health Organization.

\section{Table 1 about here}

In 1997 the Swedish government introduced a new reimbursement scheme for prescription drugs, which sharply increased the out-of-pocket costs for patients filling their prescriptions. Since the reform was announced in advance, many patients took the opportunity to hoard drugs - fill as many prescriptions as possible - during the last months of 1996 before the new scheme was in place. In the data, one can therefore see a sharp peak in the sales statistics for 1996, followed by a decline in 1997, which of course does not reflect the actual pattern of the utilization of drugs. Therefore, in order to get more accurate estimates of the actual utilization of drugs we adjust the data for 1996 and 1997 in the following manner: first the annual growth in sold quantity was calculated for the period 1995-1998, based on the numbers for the two years 1995 and 1998. Then the sold quantity for 1996 was added with the sold quantity for 1997, after which the total sold quantity for these two years was allocated so that the quantity for 1997 was higher than the quantity for 1996 by a factor equal to the calculated annual growth rate.

\footnotetext{
${ }^{2}$ The reason it will minimize bias is that there are some suicides that are never classified as suicides, for example some of the traffic accidents and some of the drowning accidents (see, e.g., the information at NASP's, the National Centre for Suicide Research and Prevention of Mental Ill-Health, web page, http://www.ki.se/suicide). As a robustness check, we will however also conduct the analysis only on those suicides that are classified as certain.
} 


\subsection{Descriptive statistics}

The claim that the increased usage of antidepressants has caused a reduction in suicide rates is usually based on graphs like the ones in Figures 1 to 3, which plots the development of the two variables during the 1990's (Figures 2 and 3 separately for men and women). Here we can see that there has been a substantial growth in the sold quantity of antidepressants during the 1990's for both men and women, although the growth has been much more dramatic for women. While men and women used about the same number of DDD's per capita in 1990, women used twice as many in 2000 .

The suicide rate has dropped for both men and women. But here the pattern is reversed: men have experienced a much steeper decline than women in absolute terms $(-10.5$ vs. -4.8 ). In relative terms, though, it is very close, $-32 \%$ vs. $-34 \%$.

\section{Figures 1-3 about here}

In Table 2 we can see, separately for different age groups, how the suicide rates and prescription rates have changed between the years 1990 and 2000. For all age groups, save $15-19$, the suicide rate has declined by some 25 to 50 percent. The largest decline in absolute numbers is found in age groups 60-64 and 50-54. Simultaneously the sold quantity of antidepressants has increased dramatically in all age groups; ranging from 270 percent in age group 15-19 to 1,260 percent in age group 20-24. The largest growth in absolute figures are in age groups 50-54 and 55-59.

There are interesting differences between some age groups. For instance, although the increase in sold quantity of antidepressants was almost the same in age groups 60-64 and 65-69, the suicide rate in 60-64 declined by half while for 65-69 it only declined by a fourth. In the age group 15-19 the suicide rate stayed roughly the same over the period, 
although there was a significant increase in the prescription of antidepressants. Both of these observations casts doubt on the hypothesis of a simple negative relation between antidepressant prescriptions and the suicide rate. The correlation between the difference in suicide rate (column 5) and the difference in sold quantity of antidepressants (column 9), although negative, is only -0.05 .

\section{Table 2 about here}

Table 3 gives the numbers for the two years 1990 and 2000 separately for the counties. All counties have seen a decline, although there are large differences, with the largest decline experienced in the county of Södermanland and the smallest in the county of Värmland. Just like for all age groups, the sold quantity of antidepressants has increased dramatically in all counties; ranging from 279 percent in the county of Kronoberg to 611 percent in the county of Stockholm. Also the county-level data provides figures that cast doubt on the hypothesis of a simple relation between the prescribing of antidepressants and the suicide rate. The suicide rates in some counties have declined very little although there has been a substantial increase in the sold quantity of antidepressants, see e.g. Östergötland, Gotland and Värmland. The correlation between the difference in suicide rate (column 5) and the difference in sold quantity of antidepressants (column 9) is somewhat larger than in table 2 , but still rather small; -0.22 .

\section{Table 3 about here}

A last piece of circumstantial evidence that casts doubt on the hypothesis of a causal relationship between the sold quantity of antidepressants and the suicide rate is the fact 
that the downturn in the suicide rate seems to have started before the utilization of antidepressants escalated; Figure 4 shows that there has been a decline in the suicide rate since the early 1980's.

\section{Figure 4 about here}

\section{Statistical specification}

We will assume that there is an underlying process that connects per capita suicide rates, $S_{i j t}$, and the sold quantity of antidepressants, $A_{i j t}$, in county $i=1, \ldots, N$, for age group $j=1, \ldots$, $C$ at time $t=1, \ldots, T$ such that

$$
S_{i j t}\left(A_{i j t}, \alpha\right)=e^{\alpha A_{j i t}}
$$

where we are interested in estimating the parameter $\alpha$. Since suicide rates are non-negative, the exponential form is suitable. Furthermore, for the exponential form, any changes are proportional to the suicide rate, which seems more plausible than for example constant changes produced by a linear relation.

Apart from the sold quantity of antidepressants, the suicide rate in a county for a certain age group in a certain year might also be determined by other, observable and unobservable, factors. Therefore, we will also control for other observable variables, $x_{i t}$, that are assumed to affect the suicide rate ${ }^{3}$ and for county-specific fixed effects, $f_{i}$, age-specific fixed effects (where ages are in five-year intervals), $f_{j}$, and time dummies, $\tau_{t}$. The countyspecific and the age-specific fixed effects control for variables that affect the suicide rate in

\footnotetext{
${ }^{3}$ The $x$-variables that we will include in the regressions are: unemployment rate, average income, divorce rate, sold quantities of alcohol, and population density. These variables are only observed at the county level for each year, not separately for each age group.
} 
the same way over time for a certain county and for a certain age group, while the time dummies control for unobservable variables that vary over time but that are assumed to affect the suicide rate in the same way for all counties and all age groups in a given year. The fixed effects and the time dummies might be correlated with the observable variables. Furthermore, the suicide rate can also be affected by disturbances, $u$. Thus, we have the following relationship to be estimated for the suicide rate

$$
S_{i j t}\left(\mathrm{~A}_{i j t}, x_{i t}, f_{i}, \tau_{t}, \alpha, \beta\right)=\mu_{i j t} e^{\alpha A_{i j t}+x_{i t} \beta} v_{i j t}
$$

where $\mu_{i j t}=e^{f_{i}+f_{j}+\tau_{t}}$ is a scaling factor of the county suicide rate for a specific age group in a specific year, and $v_{i j t}=e^{u_{i j t}}$ is the disturbance term. The most obvious way to estimate equation (1) is perhaps to take the logarithm of it and use OLS to estimate the familiar loglinear fixed effect model. However, this is a less suitable estimation strategy in the present case for different reasons related to the characteristics of the data.

A first characteristic of our data is that it contains a substantial amount of zeroes. Suicide is an uncommon event, and it is quite often the case that no suicide is committed in a certain age group, in a certain county, during a particular year. The "zeroes" create two distinct problems. First, the log-linear model cannot handle a "zero"-observation. ${ }^{4}$ Second, the distribution of the dependent variable will be skewed to the left, and a normal or indeed any other type of symmetrical distribution cannot be assumed. A solution to the "zeroes-problem" is to aggregate the units of analysis so that the dependent variable takes on a number larger than zero for all observations. ${ }^{5}$ However, in doing so some interesting questions cannot be investigated; for example, we would not be able to investigate whether

\footnotetext{
${ }^{4}$ The usual way of solving this problem is to tamper with the data and add a small number to zero-observations.

${ }^{5}$ This is typically what the earlier studies have done.
} 
there are any heterogeneous effects with respect to age or sex. In addition, we will lose observations, which will yield less precise estimates.

A second characteristic of our data is the discrete nature of them (which, of course, the "zeroes-problem" also is a consequence of). Suicides are discrete events and the number of suicides committed is an integer. While this is not a problem for larger populations, for smaller populations it is, since the discrete nature of the suicides will then transfer to the suicide rate, which is our dependent variable. For a population of 5,000, one additional suicide corresponds to 20 suicides per 100,000 inhabitants. Since the precision of suicide rate estimates as a consequence will depend on the population size, we cannot expect the variance of the regression errors to be homoscedastic, if we estimate equation (1) with common methods. The smaller the population is, the larger the variance is. ${ }^{6}$ In Figures 5 and 6 the distribution of number of suicides and the suicide rate, respectively, is shown, illustrating how the distributions are skewed.

Since the Poisson distribution is useful for modelling non-negative integer outcomes, we will in this paper make use of the fixed effects Poisson (FEP) estimator. The FEP estimator has nice robustness properties. Given that the conditional mean equation is correctly specified, including the strict exogeneity of $x_{i t}$, our estimates are consistent and asymptotically normal and we can estimate our model without further distributional assumptions (see Wooldridge, 1999). The estimates might not be efficient, however. ${ }^{7}$ Furthermore, the ordinary maximum likelihood standard errors are not valid for inference. The standard errors must be made robust against misspecification, which is straightforward (see Wooldridge, 1999). The robust standard errors might be larger or smaller than the ordinary standard errors.

\footnotetext{
${ }^{6}$ See Osgood (2000) for a discussion in a cross-sectional setting.

${ }^{7}$ Given that the assumptions for the FEP estimator are satisfied, Hahn (1997) has shown that FEP is the efficient semi-parametric estimator.
} 


\section{Figures 5-6 about here}

\section{Results}

\subsection{Baseline estimates}

In the baseline specification we will use those suicides that are classified as both "certain" and "uncertain". We will elaborate with three specifications. In the first specification, we do not control for anything else that varies over time than the sold quantity of antidepressants. ${ }^{8}$ This is in line with what the earlier studies in the field have done. In the second specification, we also control for unobserved time effects that affect the suicide rate in the same way in each county in a given year (captured through the time dummies). In the third specification, we also control for socio-economic characteristics.

From the baseline results in Table 4 it is clear that there is a negative and highly statistically significant correlation between the sold quantity of antidepressants and the suicide rate when we do not control for unobserved time effects (c.f. the results in the first column). This is what the earlier research has found (see, e.g., Isacsson, 2000). When adding time dummies (second column) and socio-economic characteristics (last column) as covariates in the model specification, the estimated standard errors for the antidepressants variable increases for both specifications, leaving the sales rate insignificant.

Regarding the socio-economic characteristics, it is clear that the unemployment rate and the amount of sold alcohol are important variables (at least in a statistical sense); the higher the unemployment rate is in a county and the more alcohol that is being sold in a county, the higher the suicide rate in the county is. ${ }^{9}$ The divorce rate, average income, and

\footnotetext{
${ }^{8}$ We do however control for unobserved county-specific fixed effects that affect the suicide rate in the same way over time in each county and for unobserved age-specific fixed effects that affect the suicide rate in the same way over time within each age group (five-year intervals).

${ }^{9}$ The unemployment rate is defined as the open unemployment in a county divided by the population in the county $(\times 100,000)$ and the alcohol variable is the amount of alcohol (measured in $100 \%$ ethanol) sold per inhabitant over 14 years of age at the state-owned company Systembolaget. The latter variable might be a
} 
population density do however not have any statistically significant effects on the suicide rate. $^{10}$

\section{Table 4 about here}

\subsection{Are there different effects for men and women?}

The descriptive statistics presented in section 2 indicated that the connection between the sold quantities of antidepressants and the suicide rate might be different for men and women (c.f. figures 2 and 3). To examine whether there are different effects of antidepressants on the suicide rate for men and women, we will run separate regressions for the two groups. ${ }^{11}$ As is clear from the results presented in Table 5, there are no statistically significant effects of the sold quantity of antidepressants on the suicide rate for any of the groups. For the socioeconomic variables, the results are similar as for all persons. The only difference is that the divorce rate seems to be important for the female suicide rate; the higher the divorce rate is the lower the female suicide rate is.

\section{Table 5 about here}

\subsection{Are there different effects in different age groups?}

That the effects might be different for different age groups is heatedly debated in several countries at the moment (especially in the US and the UK); the debate is mainly concerned with the effects from the new antidepressants on the suicide rate among children and in

\footnotetext{
somewhat problematic measure of alcohol consumption in certain counties in Sweden for the later years due to an increased consumption of alcohol from neighboring countries with a low-tax policy on alcohol.

${ }^{10}$ The divorce rate is the total number of divorces in a county in a given year divided by the population in the county $(\times 100,000)$, the income variable is average after-tax income (in thousands of Swedish kronor), and the population density is the county-population per square kilometre.

${ }^{11}$ We run two regressions for each group; one in which we, in addition to the antidepressants, only control for the unobservable characteristics and one in which we control for both the unobservable and the observable characteristics.
} 
adolescence since some researchers claim that the effect might be positive for those age groups.

To examine whether there are different effects in different age groups, we will estimate a model in which we interact the antidepressants variable with dummy variables for different age groups; for those under the age of 25 (Young), for those in the age interval 25-54 (Middle-aged), and for those above 55 (reference group). From the results presented in Table 6 , it seems like antidepressants have a positive and statistically significant effect on young people, and the economic effect seems to be approximately the same for both sexes. There are no significant effects on the suicide rate for the other age groups.

\section{Table 6 about here}

\section{Robustness checks}

We will conduct four robustness checks on the results obtained when the sold quantities of antidepressants are interacted with the age-dummies (i.e., the robustness checks will be made on the results in Table 6). First, we examine how sensitive the results are to an alternative estimation method (the log-linear fixed effects estimator) ${ }^{12}$. Second, we examine what happens when we only use those suicides that are classified as certain as the dependent variable. Third, in the baseline analysis, we implicitly assumed that there is no serial correlation in the suicide rate. However, if there is such a correlation in the error process, the resulting standard errors are inconsistently estimated and may lead to severely biased estimates in small samples (see, e.g., Kezdi, 2002, and Bertrand et al, 2004). To examine how sensitive the earlier results are to this, we reestimate a model in which we allow the errors to

\footnotetext{
${ }^{12}$ We estimate two versions of the log-linear fixed effects estimator; one where we keep the zeroes (implying that we lose observations when taking the logarithm of the suicide variable), and one where we add a one to each suicide before taking the logarithm (not to lose observations when taking the logarithm of the suicide variable).
} 
be correlated over time within each county. ${ }^{13}$ Finally, we control for county-specific time trends to allow for different (county-specific) evolutions over time for the suicide variable. The results are presented in Table 7. ${ }^{14}$ Two conclusions can be drawn. First, the baseline result that there are no significantly negative effects of the sold quantity of antidepressants on the suicide rates seems to be robust in relation to those alterations considered in Table 7 . Second, when we get a statistically significant effect, it is positive and it affects mainly young people. Also in this sense the baseline results do seem to be robust to different respecifications of the model.

\section{Conclusions}

In this paper we have reinvestigated the issue of whether the increased prescription of antidepressants can explain the simultaneous reduction in suicide rates. Using fairly detailed data on suicide rates and sold quantities of antidepressants, we find, after controlling for other covariates, observed as well as unobserved, that might affect the suicide rate, no statistically significant effects from antidepressants on the suicide rate. This result is at odds with recent research claiming that the new type of antidepressants explains the major part of the large reduction in suicide rates in several countries.

However, when we allow for heterogeneous effects on different age groups, we find a positive and statistically significant effect of sold quantities of antidepressants on the suicide rate for young persons (under the age of 25). This result seems to be robust to several alternative model specifications.

Are there any caveats with our approach? Well, the paper uses observational data to study the issue at hand (just like the papers cited in the Introduction). In the medical research community, data from clinical trials are usually preferred over observational data,

\footnotetext{
${ }^{13}$ Technically, this is done in STATA by clustering on county.

${ }^{14}$ In the table, we only report the results for the antidepressants variable and its interactions with the agedummies. The other covariates are the same as in Table 6 .
} 
since selection bias can be avoided. However, when studying the issue at hand, we think there are good reasons why observational data is to be preferred. First, suicides are rare events, and thus most trials have insufficient power to provide clear evidence. Second, most trials are of too short duration, typically 8-12 weeks, to identify the longer term effects. Third, patients taking part in trials are under more careful scrutiny than ordinary patients, so any signs of suicidal behavior could better be detected and given appropriate attention by caregivers.

Having said this, we do not find evidence from randomised trials useless. What is then the evidence from clinical trials on the connection between suicide and antidepressants? In the most comprehensive synthesis of data from randomised trials, Khan (2003) and colleagues found no evidence of a beneficial effect of antidepressants on suicide. Concerning paediatric use, Gunnel and Ashby (2004) summarise the existing body of literature as: "Data from paediatric trials suggest that SSRIs are associated with an increased risk of suicidal behavior and most SSRIs seem to be ineffective for childhood depression." Thus, the evidence from randomised trials seems to be in line with what we find.

Probably the most controversial of our results is that the likelihood of suicide seems to increase for young people when using antidepressants. However, since no policy should be changed based on the results from a single study, we do not want to stress this result too much. More research is needed before any firm conclusion can be made on this very important issue.

Another question that remains to be answered is, if it is not the increased usage of antidepressants, what is it then that explains the reduction in suicide rates? Since the reduction in suicide rates started already before the introduction of the SSRI-type of antidepressants, it is quite likely that there are some other explanations for the downturn in suicide rates. This should be a topic for future research on this issue. 


\section{References}

Barbui, C., Campomori, A., D’Avanzo, B., Negri, E. and Garattini, S. (1999). Antidepressants Drug Use in Italy Since the Introduction of SSRIs: National Trends, Regional Differences and Impact on Suicide Rates. Social psychiatry and psychiatric epidemiology 34, 152-156.

Bertrand, M., Duflo, E. and Mullainathan, S. (2004). How Much Should We Trust Differences-in-Differences Estimates? Quarterly Journal of Economics, 249-275.

Carlsten, A., Waern, M., Ekedahl, A. and Ranstam, J. (2001). Antidepressant Medication and Suicide in Sweden. Pharmacoepidemiology and drug safety 10, 525-530.

Cheng, A. T. A. (1995). Mental Illness and Suicide. Arch Gen Psychiatry 52, 594-603.

Gunnel, D. and Ashby, D. (2004). Antidepressants and Suicide: What is the Balance of Benefit and Harm?. British Medical Journal 329, 34-38.

Hahn, J. (1997). A Note on the Efficient Semiparametric Estimation of some Exponential Panel Models. Econometric Theory 13, 583-588.

Hall, W. D., Mant, A., Mitchell, P. B., Rendle, V. A., Hickie, I. B. and McManus, P. (2003). Association Between Antidepressant Prescribing and Suicide in Australia, 1991-2000: Trend Analysis. British Medical Journal 326. 
Isacsson, G., Boethius, G. and Bergman, U. (1992). Low Level of Antidepressant Prescription for People Who Later Commit Suicide: 15 Years of Experience from a Population Based Drug Database in Sweden. Acta Psychiatrica Scand 85, 444-448.

Isacsson, G., Holmgren, P., Wasserman, D. and Bergman, U. (1994). Use of Antidepressants Among People Committing Suicide in Sweden. British Medical Journal, 308, 506-509.

Isacsson, G. (2000). Suicide Prevention - A Medical Breakthrough?. Acta Psychiatrica Scandinavica 102, 113-117.

Isometsä, E. T., Henriksson, M. M., Aro, H. M., Heikkinen, M. E., Kuoppasalmi, K. I. and Lönnqvist, J. K. (1994). Suicide in Major Depression. American Journal of Psychiatry 151, $135-142$.

Kahn, A., Khan, S., Kolts, R. and Brown W. A. (2003). Suicide Rates in Clinical Trials of SSRIs, Other Antidepressants, and Placebo: Analysis of FDA Reports. American Journal of Psychiatry 160, 790-792

Kézdi, G. (2002). Robust Standard Error Estimation in Fixed-Effects Panel Models. Mimeo. University of Michigan.

Ludwig, J. and Marcotte, D. (2004). Anti-depressants, Suicide and Drug Regulation. Journal of Policy Analysis and Management 24, Number 2. 
Rihmer, Z. (2001). Can Better Recognition and Treatment of Depression Reduce Suicide Rates? A Brief Review. European Psychiatry 16, 406-409.

Osgood, D. W. (2000). Poisson-Based Regression Analysis of Aggregate Crime Rates. Journal of Quantitative Criminology, 16, 21-43.

Wooldridge, J. M. (1999). Distribution-Free Estimation of some Nonlinear Panel Data Models. Journal of Econometrics, 90, 77-97. 


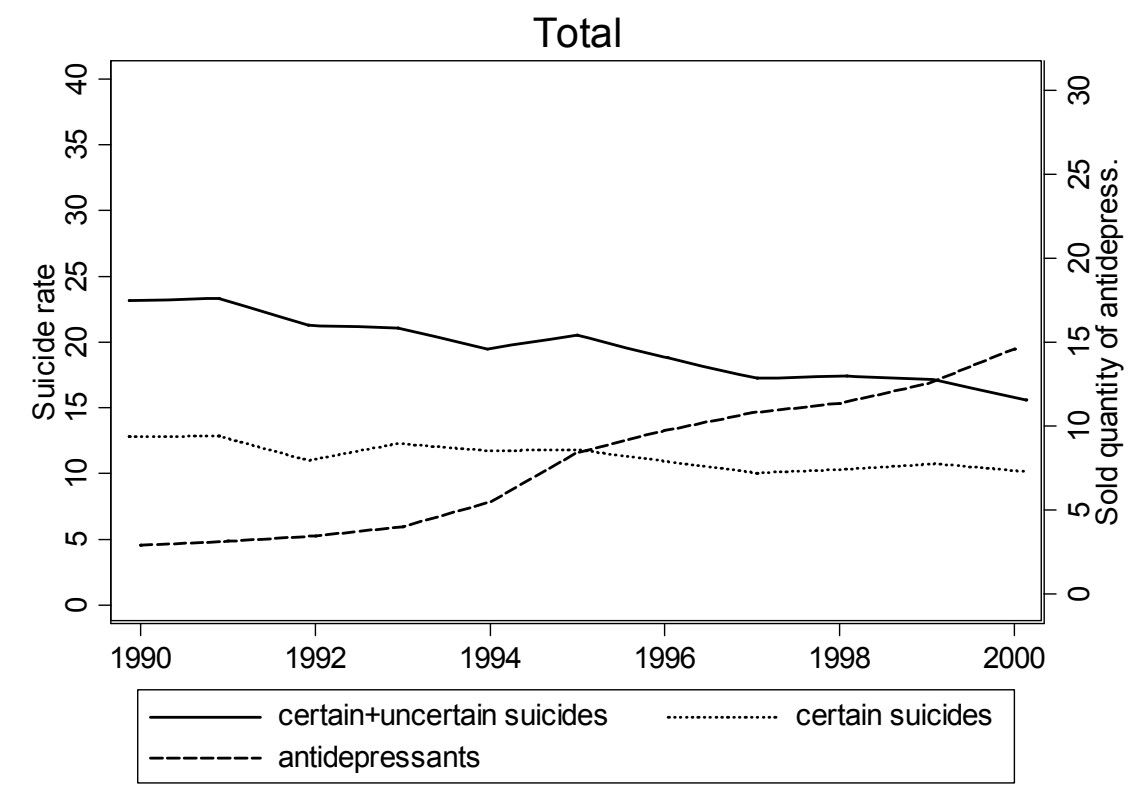

Source: Own calculations based on the data described in the paper.

Figure 1: Suicide rate and sold quantity of antidepressants over the years 1990-2000. Both men and women. 


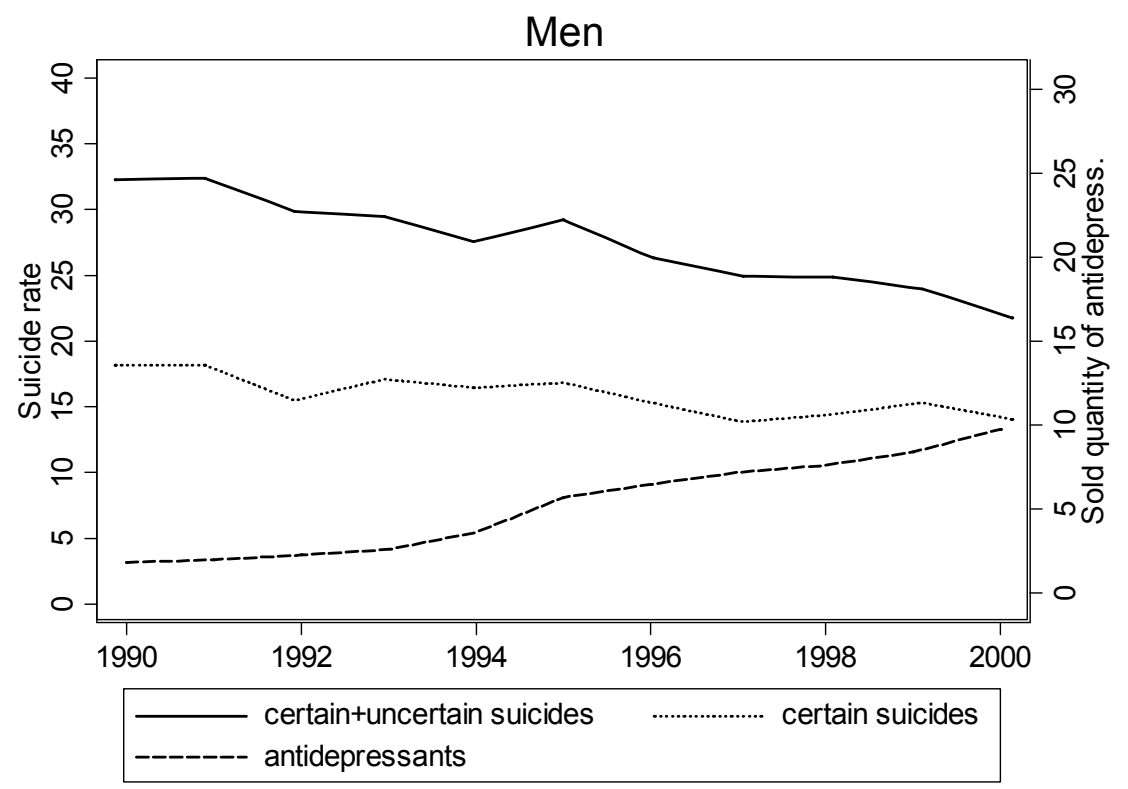

Source: Own calculations based on the data described in the paper.

Figure 2: Suicide rate and sold quantity of antidepressants for men over the years 1990-2000 


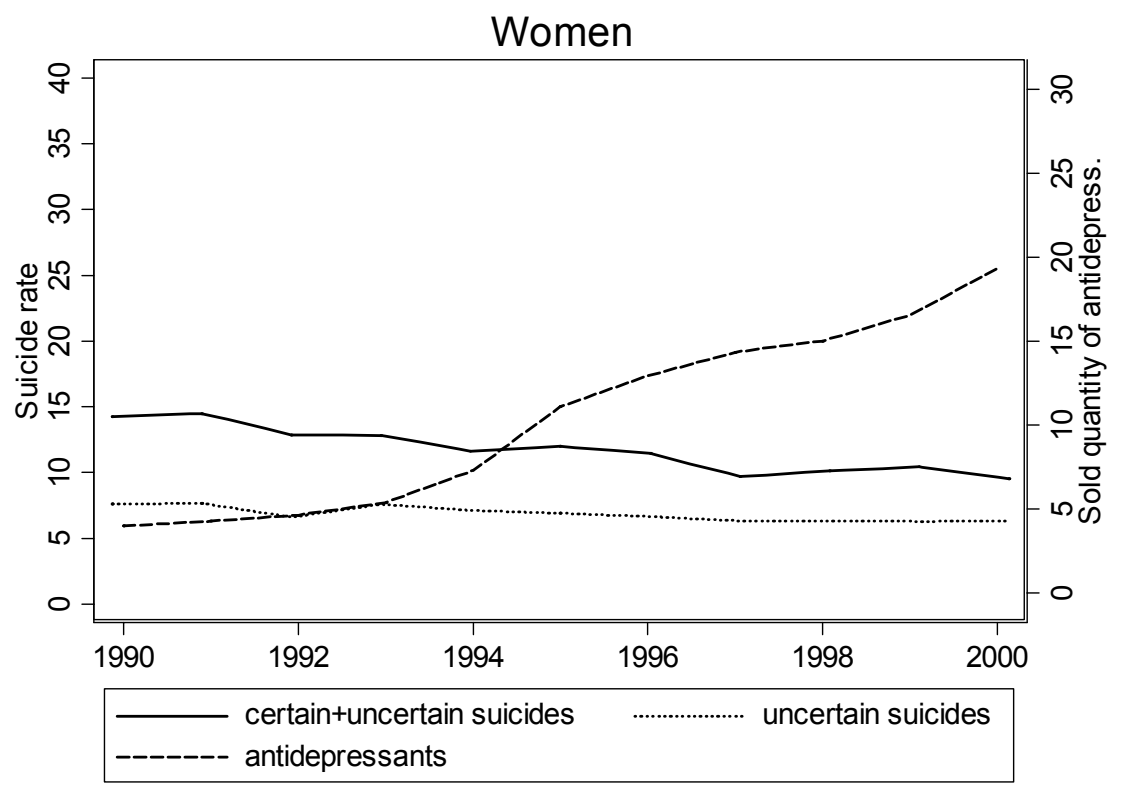

Source: Own calculations based on the data described in the paper.

Figure 3: Suicide rate and sold quantity of antidepressants for women over the years 19902000 . 


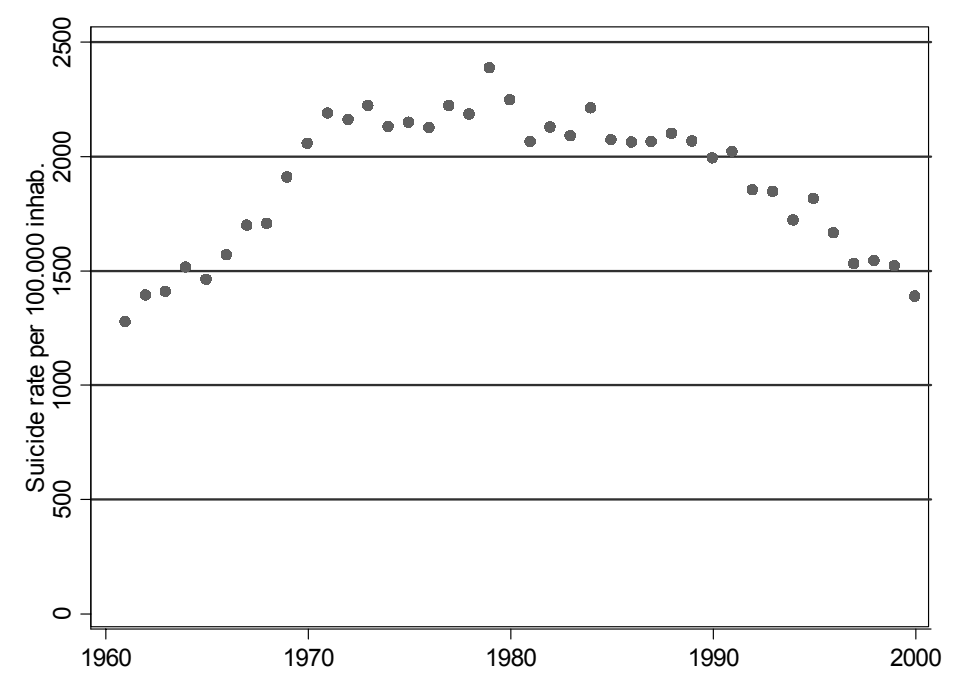

Source: Own calculations based on the data described in the paper.

Figure 4: Suicide rate 1960-2000 


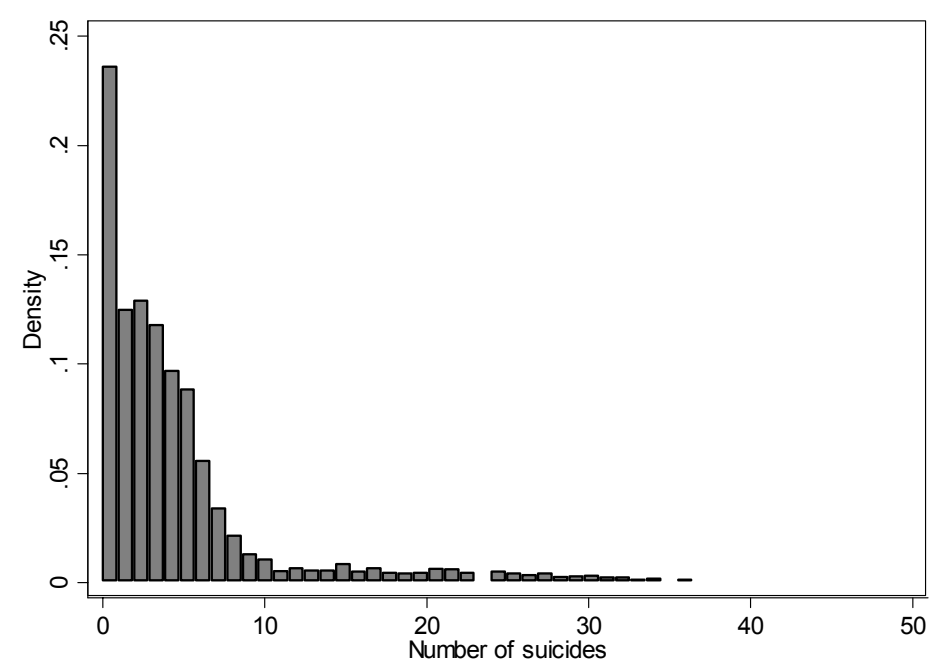

Source: Own calculations based on the data described in the paper.

Figure 5: Distribution for the number of suicides 


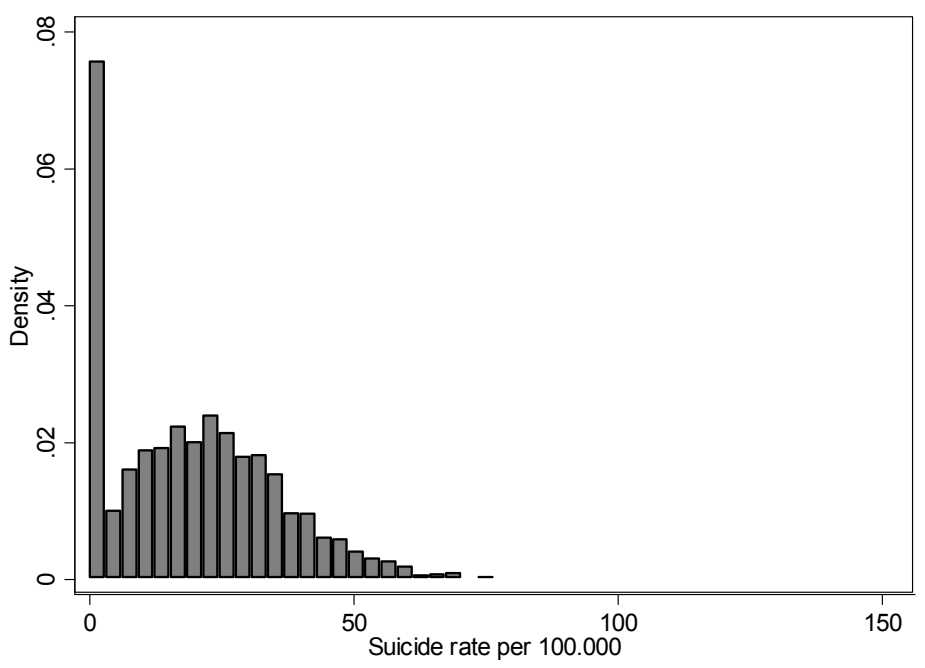

Source: Own calculations based on the data described in the paper.

Figure 6: Distribution for suicide rate 
Table 1: Summary statistics for dependent and main explanatory variables

\begin{tabular}{lcccc}
\hline \hline Variable & Mean & Std. Dev. & Min. & Max. \\
\hline Suicide rate* (certain + uncertain) & 16.74 & 16.87 & 0 & 153.31 \\
Suicide rate* (certain) & 11.09 & 13.35 & 0 & 102.18 \\
Sold quantity (in DDD's)** & 9.77 & 8.77 & 0 & 37.12 \\
\hline Number of obs. & \multicolumn{5}{c}{4646} \\
\hline
\end{tabular}

* Per 100,000 inhabitants.

** DDD's (Defined Daily Dose) per capita. 
Table 2: Suicide rates and sold quantity of antidepressants, by age group

\begin{tabular}{lcccc|cccc}
\hline \hline & \multicolumn{5}{c|}{ Suicide rate* } & \multicolumn{3}{c}{ Sold quantity of antidepress. ** } \\
Age group & 1990 & 2000 & Diff. & Diff. \% & 1990 & 2000 & Diff. & Diff. \% \\
\hline $10-14$ & 1.2 & 0.5 & -0.7 & -58 & 0.0 & 0.5 & 0.5 & $\infty$ \\
$15-19$ & 8.0 & 8.1 & 0.1 & 1 & 0.1 & 2.8 & 2.7 & 270 \\
$20-24$ & 18.0 & 12.6 & -5.4 & -30 & 0.5 & 6.8 & 6.3 & 1260 \\
$25-29$ & 19.3 & 14.2 & -5.1 & -26 & 1.3 & 9.5 & 8.2 & 630 \\
$30-34$ & 27.9 & 14.2 & -13.7 & -49 & 2.1 & 12.3 & 10.2 & 486 \\
$35-39$ & 27.0 & 19.9 & -7.1 & -26 & 3.3 & 16.2 & 12.9 & 391 \\
$40-44$ & 30.5 & 20.0 & -10.5 & -34 & 3.7 & 19.5 & 15.8 & 427 \\
$45-49$ & 33.0 & 21.9 & -11.1 & -34 & 4.4 & 21.9 & 17.5 & 398 \\
$50-54$ & 35.7 & 21.3 & -14.4 & -40 & 5.0 & 23.6 & 18.6 & 372 \\
$55-59$ & 35.6 & 22.8 & -12.8 & -36 & 5.6 & 24.6 & 19 & 339 \\
$60-64$ & 37.5 & 18.8 & -18.7 & -50 & 5.6 & 22.4 & 16.8 & 300 \\
$65-69$ & 31.8 & 23.3 & -8.5 & -27 & 5.6 & 21.2 & 15.6 & 279 \\
$70-74$ & 32.7 & 24.3 & -8.4 & -26 & 5.6 & 23.6 & 18.0 & 321 \\
$75-79$ & 38.2 & 25.4 & -12.8 & -34 & 6.0 & 26.4 & 20.4 & 340 \\
$80-$ & 32.7 & 25.0 & -7.7 & -24 & 5.6 & 25.6 & 20.0 & 357 \\
\hline$*$ per & 300,000 & & & & & & &
\end{tabular}

* per 100,000 inhabitants

* DDD's per capita

Source: Own calculations based on the data described in the paper. 
Table 3: Suicide rates and sold quantity of antidepressants, by county

\begin{tabular}{|c|c|c|c|c|c|c|c|c|}
\hline \multirow[b]{2}{*}{ County } & \multicolumn{4}{|c|}{ Suicide rate* } & \multicolumn{4}{|c|}{ Sold quantity of antidepress. ${ }^{* *}$} \\
\hline & 1990 & 2000 & Diff. & Diff. $\%$ & 1990 & 2000 & Diff. & Diff. $\%$ \\
\hline Stockholm & 26.4 & 15.6 & -10.8 & -40.1 & 1.9 & 13.5 & 11.6 & 611 \\
\hline Uppsala & 24.2 & 14.3 & -9.9 & -40.1 & 3.3 & 16.1 & 12.8 & 388 \\
\hline Södermanland & 16.8 & 9.4 & -7.4 & -44.0 & 2.8 & 15.5 & 12.7 & 454 \\
\hline Östergötland & 19.6 & 17.0 & -2.6 & -13.3 & 3.0 & 15.5 & 12.5 & 417 \\
\hline Jönköping & 17.5 & 12.2 & -5.3 & -30.3 & 3.5 & 14.7 & 11.2 & 320 \\
\hline Kronoberg & 21.9 & 18.7 & -3.2 & -14.6 & 3.9 & 14.8 & 10.9 & 279 \\
\hline Kalmar & 17.0 & 11.5 & -5.5 & -32.3 & 2.4 & 13.6 & 11.2 & 467 \\
\hline Gotland & 29.8 & 26.2 & -3.6 & -12.1 & 2.3 & 14.3 & 12.0 & 522 \\
\hline Blekinge & 21.9 & 13.3 & -8.6 & -39.3 & 2.7 & 13.9 & 11.2 & 415 \\
\hline Skåne & 26.7 & 15.5 & -11.2 & -41.9 & 3.4 & 16.2 & 12.8 & 376 \\
\hline Halland & 22.8 & 17.1 & -5.7 & -25.0 & 3.0 & 13.6 & 10.6 & 353 \\
\hline Västra Götaland & 22.5 & 15.8 & -6.7 & -29.8 & 4.2 & 15.7 & 11.5 & 274 \\
\hline Värmland & 21.9 & 21.1 & -0.8 & -3.6 & 3.8 & 16.1 & 12.3 & 324 \\
\hline Örebro & 21.3 & 13.2 & -8.1 & -38.0 & 2.0 & 12.2 & 10.2 & 510 \\
\hline Västmanland & 24.8 & 17.1 & -7.7 & -31.0 & 2.7 & 14.3 & 11.6 & 430 \\
\hline Dalarna & 24.6 & 19.0 & -5.6 & -22.8 & 2.7 & 14.1 & 11.4 & 422 \\
\hline Gävleborg & 21.4 & 16.5 & -4.9 & -22.9 & 2.6 & 14.8 & 12.2 & 469 \\
\hline Västernorrland & 20.3 & 15.8 & -4.5 & -22.2 & 2.0 & 12.7 & 10.7 & 535 \\
\hline Jämtland & 25.0 & 20.8 & -4.2 & -16.8 & 2.4 & 14.4 & 12.0 & 500 \\
\hline Västerbotten & 17.1 & 12.1 & -5.0 & -29.2 & 2.2 & 14.0 & 11.8 & 536 \\
\hline Norrbotten & 25.4 & 14.8 & -10.6 & -41.7 & 1.8 & 10.7 & 8.9 & 494 \\
\hline
\end{tabular}

* per 100,000 inhabitants

** DDD's per capita

Source: Own calculations based on the data described in the paper. 
Table 4. Baseline estimates: all individuals.

\begin{tabular}{|c|c|c|c|}
\hline \multirow[t]{2}{*}{ Antidepressants } & $-0.020 * * *$ & 0.0009 & 0.0021 \\
\hline & $(0.0013)$ & $(0.0034)$ & $(0.0033)$ \\
\hline \multirow[t]{2}{*}{ Unemployment } & & & $0.00006 * * *$ \\
\hline & & & $(0.00002)$ \\
\hline \multirow[t]{2}{*}{ Income } & & & 0.0024 \\
\hline & & & $(0.0059)$ \\
\hline \multirow[t]{2}{*}{ Divorced } & & & -0.00006 \\
\hline & & & $(0.00012)$ \\
\hline \multirow[t]{2}{*}{ Alcohol } & & & $0.1182 * * *$ \\
\hline & & & $(0.0428)$ \\
\hline \multirow[t]{2}{*}{ Population density } & & & -0.0039 \\
\hline & & & $(0.0042)$ \\
\hline $\mathrm{FE}_{\text {county }}$ & Yes & Yes & Yes \\
\hline $\mathrm{FE}_{\text {age group }}$ & Yes & Yes & Yes \\
\hline Time dummies & No & Yes & Yes \\
\hline Obs. & 3465 & 3465 & 3399 \\
\hline
\end{tabular}

Notes: Robust standard errors are presented in brackets. ${ }^{* * *},{ }^{* *}$, and * denotes significance at the 1,5 , and 10 percent significance level respectively. $\mathrm{FE}_{\text {county }}$ denotes county-specific fixed effects, and $\mathrm{FE}_{\text {age group }}$ denotes agespecific fixed effects. 
Table 5. Separate regressions for men and women.

\begin{tabular}{|c|c|c|c|c|}
\hline \multirow[b]{2}{*}{ Antidepressants } & \multicolumn{2}{|c|}{ Men } & \multicolumn{2}{|c|}{ Women } \\
\hline & 0.0025 & .0040 & 0.0020 & .0026 \\
\hline & $(0.0050)$ & $(.0049)$ & $(0.0048)$ & $(.0048)$ \\
\hline \multirow[t]{2}{*}{ Unemployment } & & $.00006 * * *$ & & $.00007 * *$ \\
\hline & & $(.00002)$ & & $(.00003)$ \\
\hline \multirow[t]{2}{*}{ Income } & & .0093 & & -.014 \\
\hline & & $(.0069)$ & & $(.011)$ \\
\hline \multirow[t]{2}{*}{ Divorced } & & .0001 & & $-.0005 * *$ \\
\hline & & $(.00015)$ & & $(.00023)$ \\
\hline \multirow[t]{2}{*}{ Alcohol } & & $.1092 * *$ & & $.143 *$ \\
\hline & & $(.0518)$ & & $(.0774)$ \\
\hline \multirow[t]{2}{*}{ Population density } & & -.0007 & & -.011 \\
\hline & & $(.0050)$ & & $(.0076)$ \\
\hline $\mathrm{FE}_{\text {county }}$ & Yes & Yes & Yes & Yes \\
\hline $\mathrm{FE}_{\text {age group }}$ & Yes & Yes & Yes & Yes \\
\hline Time dummies & Yes & Yes & Yes & Yes \\
\hline Obs. & 3465 & 3399 & 3465 & 3399 \\
\hline
\end{tabular}

Notes: Robust standard errors are presented in brackets. $* * *, * *$, and $*$ denotes significance at the 1,5 , and 10 percent significance level respectively. $\mathrm{FE}_{\text {county }}$ denotes county-specific fixed effects, and $\mathrm{FE}_{\text {age group }}$ denotes agespecific fixed effects. 
Table 6. Examining whether there are any idiosyncratic effects with respect to age.

\begin{tabular}{|c|c|c|c|}
\hline & All & Men & Women \\
\hline \multirow[t]{2}{*}{ Antidepressants } & $0.006^{*}$ & .0074 & 0.0072 \\
\hline & $(0.0036)$ & $(.0051)$ & $(0.0050)$ \\
\hline \multirow[t]{2}{*}{ Antidep. $\times$ Young } & $0.048 * * *$ & $0.060 * *$ & $0.061 * *$ \\
\hline & $(0.0168)$ & $(0.029)$ & $(0.0256)$ \\
\hline \multirow[t]{2}{*}{ Antidep. $\times$ Middle age } & 0.002 & 0.005 & 0.0016 \\
\hline & $(0.0026)$ & $(0.0045)$ & $(0.0033)$ \\
\hline \multirow[t]{2}{*}{ Unemployment } & $0.00006^{* * *}$ & $.00006 * * *$ & $.00007 * *$ \\
\hline & $(0.00002)$ & $(.00002)$ & $(.00003)$ \\
\hline \multirow[t]{2}{*}{ Income } & 0.0028 & .0097 & -.014 \\
\hline & $(0.0059)$ & $(.0069)$ & $(.011)$ \\
\hline \multirow[t]{2}{*}{ Divorced } & -0.00005 & .0001 & $-.0005 * *$ \\
\hline & $(0.00012)$ & $(.00015)$ & $(.00023)$ \\
\hline \multirow[t]{2}{*}{ Alcohol } & $0.1155^{* * *}$ & $.1071 * *$ & $.139 *$ \\
\hline & $(0.0426)$ & $(.0516)$ & $(.0772)$ \\
\hline \multirow[t]{2}{*}{ Population density } & -0.0039 & -.0008 & -.011 \\
\hline & $(0.0042)$ & $(.0050)$ & $(.0075)$ \\
\hline $\mathrm{FE}_{\text {county }}$ & Yes & Yes & Yes \\
\hline $\mathrm{FE}_{\text {age group }}$ & Yes & Yes & Yes \\
\hline Time dummies & Yes & Yes & Yes \\
\hline Obs. & 3399 & 3399 & 3399 \\
\hline
\end{tabular}

Notes: Robust standard errors are presented in brackets. ***,**, and * denotes significance at the 1,5 , and 10 percent significance level respectively. $\mathrm{FE}_{\text {county }}$ denotes county-specific fixed effects, and $\mathrm{FE}_{\text {age group }}$ denotes agespecific fixed effects. 
Table 7. Robustness checks on estimation method and on classification of suicides.

\begin{tabular}{|c|c|c|c|}
\hline & All & Men & Women \\
\hline \multicolumn{4}{|l|}{ Log-linear (with zeros) } \\
\hline \multirow[t]{2}{*}{ Antidepressants } & 0.001 & .001 & 0.002 \\
\hline & $(0.0042)$ & $(.0050)$ & $(0.0037)$ \\
\hline \multirow[t]{2}{*}{ Antidep. $\times$ Young } & $0.041 * *$ & $0.082 * * *$ & 0.007 \\
\hline & $(0.0205)$ & $(0.0270)$ & $(0.0203)$ \\
\hline \multirow[t]{2}{*}{ Antidep. $\times$ Middle age } & -0.002 & 0.002 & 0.002 \\
\hline & $(0.0034)$ & $(0.0053)$ & $(0.0028)$ \\
\hline Obs. & 3024 & 2856 & 2031 \\
\hline \multicolumn{4}{|l|}{ Log-linear (no zeros) } \\
\hline \multirow[t]{2}{*}{ Antidepressants } & -0.0008 & .0001 & -0.0008 \\
\hline & $(0.0035)$ & $(.0040)$ & $(0.0026)$ \\
\hline \multirow[t]{2}{*}{ Antidep. $\times$ Young } & 0.019 & 0.036 & $0.023 * *$ \\
\hline & $(0.0169)$ & $(0.0246)$ & $(0.0106)$ \\
\hline \multirow[t]{2}{*}{ Antidep. $\times$ Middle age } & -0.003 & -0.001 & -0.002 \\
\hline & $(0.0030)$ & $(0.0045)$ & $(0.0024)$ \\
\hline Obs. & 3399 & 3399 & 3399 \\
\hline \multicolumn{4}{|l|}{ Only certain suicides } \\
\hline \multirow[t]{2}{*}{ Antidepressants } & 0.00002 & -.002 & 0.004 \\
\hline & $(0.0067)$ & $(.0089)$ & $(0.0078)$ \\
\hline \multirow[t]{2}{*}{ Antidep. $\times$ Young } & -0.011 & -0.060 & $0.053 *$ \\
\hline & $(0.0340)$ & $(0.0564)$ & $(0.0331)$ \\
\hline \multirow[t]{2}{*}{ Antidep. $\times$ Middle age } & -0.004 & -0.009 & 0.002 \\
\hline & $(0.0054)$ & $(0.0099)$ & $(0.0065)$ \\
\hline Obs & 3399 & 3399 & 3399 \\
\hline \multicolumn{4}{|c|}{ Allowing for autocorrelation in the residuals } \\
\hline \multirow[t]{2}{*}{ Antidepressants } & 0.006 & .007 & 0.007 \\
\hline & $(0.0047)$ & $(.0066)$ & $(0.0047)$ \\
\hline \multirow[t]{2}{*}{ Antidep. $\times$ Young } & $0.048 * *$ & 0.060 & $0.061 * * *$ \\
\hline & $(0.0207)$ & $(0.0389)$ & $(0.0211)$ \\
\hline \multirow[t]{2}{*}{ Antidep. $\times$ Middle age } & 0.002 & 0.005 & 0.002 \\
\hline & $(0.0030)$ & $(0.0049)$ & $(0.0034)$ \\
\hline Obs & 3399 & 3399 & 3399 \\
\hline \multicolumn{4}{|c|}{ County-specific time trends } \\
\hline \multirow[t]{2}{*}{ Antidepressants } & 0.007 & .007 & 0.010 \\
\hline & $(0.0050)$ & $(.0068)$ & $(0.0048)$ \\
\hline \multirow[t]{2}{*}{ Antidep. $\times$ Young } & $0.0519 * *$ & 0.060 & $0.068 * * *$ \\
\hline & $(0.0215)$ & $(0.0396)$ & $(0.0206)$ \\
\hline \multirow[t]{2}{*}{ Antidep. $\times$ Middle age } & 0.002 & 0.005 & 0.002 \\
\hline & $(0.0030)$ & $(0.0049)$ & $(0.0034)$ \\
\hline Obs & 3399 & 3399 & 3399 \\
\hline
\end{tabular}

Notes: Robust standard errors are presented in brackets. ***,**, and * denotes significance at the 1,5 , and 10 percent significance level respectively. In all specifications we use the same controls as in Table 6 . 
WORKING PAPERS*

Editor: Nils Gottfries

2003:24 N. Anders Klevmarken, On Household Wealth Trends in Sweden over the 1990s. 20 pp.

2003:25 Mats A. Bergman, When Should an Incumbent Be Obliged to Share its Infrastructure with an Entrant Under the General Competition Rules? 21 pp.

2003:26 Niclas Berggren and Henrik Jordahl, Does Free Trade Really Reduce Growth? Further Testing Using the Economic Freedom Index. 19 pp.

2003:27 Eleni Savvidou, The Relationship Between Skilled Labor and Technical Change. $44 \mathrm{pp}$.

2003:28 Per Pettersson-Lidbom and Matz Dahlberg, An Empirical Approach for Evaluating Soft Budget Contraints. 31 pp.

2003:29 Nils Gottfries, Booms and Busts in EMU. 34 pp.

2004:1 Iida Häkkinen, Working while enrolled in a university: Does it pay? 37 pp.

2004:2 Matz Dahlberg, Eva Mörk and Hanna Ågren, Do Politicians’ Preferences Correspond to those of the Voters? An Investigation of Political Representation. 34 pp.

2004:3 Lars Lindvall, Does Public Spending on Youths Affect Crime Rates? 40 pp.

2004:4 Thomas Aronsson and Sören Blomquist, Redistribution and Provision of Public Goods in an Economic Federation. 23 pp.

2004:5 Matias Eklöf and Daniel Hallberg, Private Alternatives and Early Retirement Programs. 30 pp.

2004:6 Bertil Holmlund, Sickness Absence and Search Unemployment. 38 pp.

2004:7 Magnus Lundin, Nils Gottfries and Tomas Lindström, Price and Investment Dynamics: An Empirical Analysis of Plant Level Data. 41 pp.

2004:8 Maria Vredin Johansson, Allocation and Ex Ante Cost Efficiency of a Swedish Subsidy for Environmental Sustainability: The Local Investment Program. 26 pp.

2004:9 Sören Blomquist and Vidar Christiansen, Taxation and Heterogeneous Preferences. 29 pp.

2004:10 Magnus Gustavsson, Changes in Educational Wage Premiums in Sweden: 1992-2001. 36 pp.

\footnotetext{
* A list of papers in this series from earlier years will be sent on request by the department.
} 
2004:11 Magnus Gustavsson, Trends in the Transitory Variance of Earnings: Evidence from Sweden 1960-1990 and a Comparison with the United States. 63 pp.

2004:12 Annika Alexius, Far Out on the Yield Curve. 41 pp.

2004:13 Pär Österholm, Estimating the Relationship between Age Structure and GDP in the OECD Using Panel Cointegration Methods. 32 pp.

2004:14 Per-Anders Edin and Magnus Gustavsson, Time Out of Work and Skill Depreciation. $29 \mathrm{pp}$.

2004:15 Sören Blomquist and Luca Micheletto, Redistribution, In-Kind Transfers and Matching Grants when the Federal Government Lacks Information on Local Costs. 34 pp.

2004:16 Iida Häkkinen, Do University Entrance Exams Predict Academic Achievement? 38 pp.

2004:17 Mikael Carlsson, Investment and Uncertainty: A Theory-Based Empirical Approach. 27 pp.

2004:18 N. Anders Klevmarken, Towards an Applicable True Cost-of-Living Index that Incorporates Housing. 8 pp.

2004:19 Matz Dahlberg and Karin Edmark, Is there a "Race-to-the-Bottom" in the Setting of Welfare Benefit Levels? Evidence from a Policy Intervention. $34 \mathrm{pp}$.

2004:20 Pär Holmberg, Unique Supply Function Equilibrium with Capacity Constraints. $31 \mathrm{pp}$.

2005:1 Mikael Bengtsson, Niclas Berggren and Henrik Jordahl, Trust and Growth in the 1990s - A Robustness Analysis. 30 pp.

2005:2 Niclas Berggren and Henrik Jordahl, Free to Trust? Economic Freedom and Social Capital. 31 pp.

2005:3 Matz Dahlberg and Eva Mörk, Public Employment and the Double Role of Bureaucrats. 26 pp.

2005:4 Matz Dahlberg and Douglas Lundin, Antidepressants and the Suicide Rate: Is There Really a Connection? $31 \mathrm{pp}$.

See also working papers published by the Office of Labour Market Policy Evaluation http://www.ifau.se/ 